\title{
Channel Characteristics for Fixed and Portable DTV Reception in a Single Frequency Network
}

\author{
Maurício V. Guerra ${ }^{1}$ (D) Jair L. de A. Filho ${ }^{1}$ (D) Carlos V. Rodriguez Ron ${ }^{2}$ (D), \\ Luiz A. R. da Silva Mello ${ }^{3}$, Pedro V. G. Castellanos ${ }^{4}$ \\ ${ }^{1}$ CEFET/RJ - Centro Federal de Educação Tecnológica Celso Suckow da Fonseca, Rio de Janeiro, Estrada de \\ Adrianópolis, 1.317, Santa Rita, Nova Iguaçu, RJ,26041-271, Brazil, mauricio.guerra@cefet-rj.br and \\ jairfilho_el@hotmail.com \\ ${ }^{2}$ Inmetro - Instituto Nacional de Metrologia, Qualidade e Tecnologia, Xerém, RJ, Brazil, \\ cvron@colaborador.inmetro.gov.br \\ ${ }^{3}$ Center for Telecommunication Studies - Catholic University of Rio de Janeiro Rio de Janeiro, R. Marquês de \\ São Vicente, 225, Gávea, Ed. Kennedy, $7^{\circ}$ andar, Rio de Janeiro, RJ, 22453-900, Brazil, smello@cetuc.puc- \\ rio.br \\ ${ }^{4}$ Universidade Federal Fluminense, Niterói, Brazil, Rua Passo da Patria, 156, São Domingos, Bloco D, Sala \\ 504 Niterói, RJ, 24210-240,Brazil, pcastellanos@id.uff.br
}

\begin{abstract}
This paper presents the propagation channel characteristics of a digital TV single-frequency network (SFN) obtained by carrying out field measurements using two synchronized transmitters. The measurements are performed at 31 reception points using both a directive reception antenna, which is typical of fixed reception scenarios, and an omnidirectional antenna, which is used to receive mobile signals. The characteristic parameters of the channel are obtained, including the average delay, the root mean square (RMS) delay spread, and the Rician K-factor, which are important for the design of SFN systems. An empirical expression is obtained for the prediction of the RMS delay spread as a function of the $\mathrm{K}$ factor and the distances to the transmission antennas.
\end{abstract}

Index Terms - SFN, DTV, multipath channel, RMS delay spread.

\section{INTRODUCTION}

Single-frequency network (SFN) transmission in digital terrestrial television systems is notably different from the traditional single-transmitter mode. Additional transmitters can improve the coverage. but also increase the multipath effect owing to the presence of reflected and signals that are transmitted from different sources reaching the receiver. The occurrence of severe multipath propagation at the receiver is known as the SFN effect and is particularly significant for portable systems that use omnidirectional reception antennas.

In a previous paper [1], field measurements in a dual-site SFN network were reported, and initial results that were presented include the cumulative distribution of the path loss and average values of the average excess delay and root mean square (RMS) delay spread (RDS) measured with directional antennas. In this paper, the data collected in that experiment are further analyzed to provide the RDS and the Rician K-factor for portable reception with an omnidirectional antenna, and fixed reception with a directional antenna at the same 31 measurement points, as well as the Rician K-factor. These 
Journal of Microwaves, Optoelectronics and Electromagnetic Applications, Vol. 18, No. 3, September 2019440 DOI: http://dx.doi.org/10.1590/2179-10742019v18i31778

parameters are used to characterize the multipath behavior in the SFN network, and an empirical expression was obtained for the relation between them.

Many past studies have analyzed SFNs and issues related to their implementation. In [2], principles and properties of SFNs in digital terrestrial broadcasting, where basic definitions and contextual relationships such as the guard interval, SFN area, and influence of the used modulation parameters are explained.

Additional works regarding the evolutionary state-of-art are proposed in [3-7]. In [3], the author presents a design performed for the DVB-T digital terrestrial television network in Greece. Optimal SFN network configurations for second generation digital terrestrial broadcast system (DVB-T2) are obtained in [4]. In [5], the authors estimate the reception quality under the SFN environment with the delay spread of two transmitters shorter than the guard interval. In [6], the SFN threshold reception for broadcasting is obtained by analyzing and evaluating the effects of the delay time between two SFN transmitters within the guard interval time. The minimum reception threshold in single-input-singleoutput (SISO) mode SFN broadcasting is analyzed in [7].

The flexibility and configuration options provided by the new DVB terrestrial standard have been proposed in [8], [9]. In the same way, measurements of simulated and real channel characteristics in the digital video broadcasting-terrestrial (DVB-T2) system were presented in [10], [11]. Compared with the SISO mode presented in [1], where significant destructive spectral interference is translated to higher bit error rate (BER) values, in these two works the DVB-T2 advanced multiple-input singleoutput (MISO) transmission technique has been shown to be a primary contributing factor associated with the actual digital television (DTV) platforms that fulfill modern technical requirements, and which meet user and market demands for HDTV services.

Section II of this paper describes the measurement campaign, which was carried out in the coverage area of a two-transmitter SFN network operating in the UHF band in the city of Rio de Janeiro, Brazil. Section III gives a brief overview of wideband channel characterization, including the definition of the channel characteristic parameters.

Section IV includes the main contributions of the paper. The analysis of the behavior of the RDS for fixed and portable reception is presented. The characteristic parameters of the channel are obtained, including the average delay, the root mean square (RMS) delay spread, and the Rician K-factor, which are important for the design of SFN systems. An empirical expression is obtained for the prediction of the RMS delay spread as a function of the $\mathrm{K}$ factor and the distances to the transmission antennas. The paper conclusions are presented in section $\mathrm{V}$.

\section{MEASUREMENT CAMPAIGN}

The measurement campaign was performed within the coverage area of a commercial broadcast SFN network operating with the ISDB-T standard, and was deployed in a suburban area in Rio de Janeiro, Brazil. Compared with digital video broadcasting-terrestrial (DVB-T), the Japanese/Brazilian standard 
Journal of Microwaves, Optoelectronics and Electromagnetic Applications, Vol. 18, No. 3, September 2019441 DOI: http://dx.doi.org/10.1590/2179-10742019v18i31778

(ISDB-T) provides important improvements. The key technology bandwidth segmented transmission orthogonal frequency-division multiplex (BST-OFDM) enables ISDB-T to support multiple services [12], [13] over the same channel, including portable and fixed reception. In addition, a longer interleave (guard-interval) is used to improve the mobile reception performance. The main system transmission parameters include the carrier modulation scheme, the coding rate of the inner error-correcting code, and the length of time interleaving, which can be set individually for each segment. The ISDB-T offers three transmission modes having different carrier intervals to deal with a variety of channel conditions, such as the multipath (mitigated with the variable guard interval as determined by the network configuration) and the Doppler shift, which occurs for mobile reception. Table I lists the basic parameters of each mode.

TABLE I. TRANSMISSION PARAMETERS FOR THE ISDB-T STANDARD.

\begin{tabular}{|c|c|c|c|c|}
\hline \multirow{2}{*}{$\begin{array}{l}\text { Description } \\
\text { No. of OFDM segments }\end{array}$} & & \multicolumn{3}{|c|}{ Transmission parameters } \\
\hline & & \multicolumn{3}{|l|}{13} \\
\hline \multicolumn{2}{|l|}{ Segment bandwidth } & \multicolumn{3}{|c|}{$428.57 \mathrm{kHz}$} \\
\hline Mode & & 1 & 2 & 3 \\
\hline No. of carriers per segment & & 108 & 216 & 432 \\
\hline No. of carriers & & 1405 & 2809 & 5617 \\
\hline Carrier interval & & $3968 \mathrm{~Hz}$ & $1984 \mathrm{~Hz}$ & $992 \mathrm{~Hz}$ \\
\hline Effective symbol length $(\mathrm{Tu})$ & & $252 \mu \mathrm{s}$ & $504 \mu \mathrm{s}$ & $1008 \mu \mathrm{s}$ \\
\hline \multirow{5}{*}{ Guard-interval length $(\mathrm{Tg}) \mu \mathrm{s}$} & $1 / 4$ & 63 & 126 & 252 \\
\hline & $1 / 8$ & 31.5 & 63 & 126 \\
\hline & $1 / 16$ & 15.75 & 31.5 & 63 \\
\hline & $1 / 32$ & 7.87 & 15.75 & 31.5 \\
\hline & $1 / 4$ & 315 & 628 & 1260 \\
\hline \multirow{3}{*}{ Symbol length per segment $\mu \mathrm{s}$} & $1 / 8$ & 283.5 & 565 & 1134 \\
\hline & $1 / 16$ & 267.7 & 533.5 & 1071 \\
\hline & $1 / 32$ & 259.8 & 517.7 & 1039.5 \\
\hline Carrier modulation & & \multicolumn{3}{|c|}{ QPSK, 16QAM, 64QAM, DQPSK } \\
\hline No. of symbols per frame & & \multicolumn{3}{|l|}{204} \\
\hline Inner code & & \multicolumn{3}{|c|}{ Convolutional coding $(1 / 2,2 / 3,3 / 4,5 / 6,7 / 8)$} \\
\hline
\end{tabular}

The measurement setup uses OFDM modulation in the ISDBT-T system to allow the evaluation of the RDS parameter by processing signals received from regular transmissions. Two transmitters, one at the peak of the Sumare mountain and the other on the top of the Pena hill, were used to broadcast the same signal [1]. The parameters of the transmitted OFDM signal used in this particular experiment are shown in Table II.

TABLE II. SFN TRANSMISSION PARAMETERS

\begin{tabular}{|c|c|c|c|c|c|c|c|c|}
\hline \multirow{2}{*}{$\begin{array}{l}\text { Channel } \\
\text { bandwidth } \\
(\mathrm{MHz})\end{array}$} & \multicolumn{3}{|c|}{$\begin{array}{c}\text { Mode } 1-2 \mathrm{k}\left(\mathrm{K}_{\mathrm{T}}=\mathrm{Tg} / \mathrm{Ts}=1 / 16\right) \\
\text { QPSK - Mobile reception } \\
\text { Omnidirectional antenna }\end{array}$} & \multicolumn{3}{|c|}{$\begin{array}{c}\text { Mode } 3-8 \mathrm{k}\left(\mathrm{K}_{\mathrm{T}}=\mathrm{Tg} / \mathrm{Ts}=1 / 16\right) \\
\text { 64QAM - Fixed reception } \\
\text { Directional antenna }\end{array}$} & \multirow{2}{*}{$\begin{array}{l}\text { Sumaré } \\
\text { Transmitter } \\
\text { Power } \\
\text { (Watts) }\end{array}$} & \multirow{2}{*}{$\begin{array}{l}\text { Pena } \\
\text { Transmitter } \\
\text { Power } \\
\text { (Watts) }\end{array}$} \\
\hline & $\mathrm{T}_{\mathrm{g}}(\mu \mathrm{s})$ & Ts $(\mu \mathrm{s})$ & $\begin{array}{c}\text { Antenna } \\
\text { Gain }\end{array}$ & $\mathrm{T}_{\mathrm{g}}(\mu \mathrm{s})$ & Ts $(\mu \mathrm{s})$ & $\begin{array}{c}\text { Antenna } \\
\text { Gain (dBi) }\end{array}$ & & \\
\hline 6 & 15.75 & 252 & 1 & 63 & 1008 & 14 & $6 \mathrm{k}$ & 100 \\
\hline
\end{tabular}


Journal of Microwaves, Optoelectronics and Electromagnetic Applications, Vol. 18, No. 3, September 2019442 DOI: http://dx.doi.org/10.1590/2179-10742019v18i31778

The mobile unit and the receiver set-up are shown in Fig. 1. It includes a low noise amplifier (LNA) which is connected to a vector analyzer and the set top box used to display the received signal. The data acquisition module was also in the mobile unit in order to perform the filtering of the collected signals and the necessary processing. On the top of the mast of the mobile unit it is possible to see the two reception antennas used in the measurement campaigns.
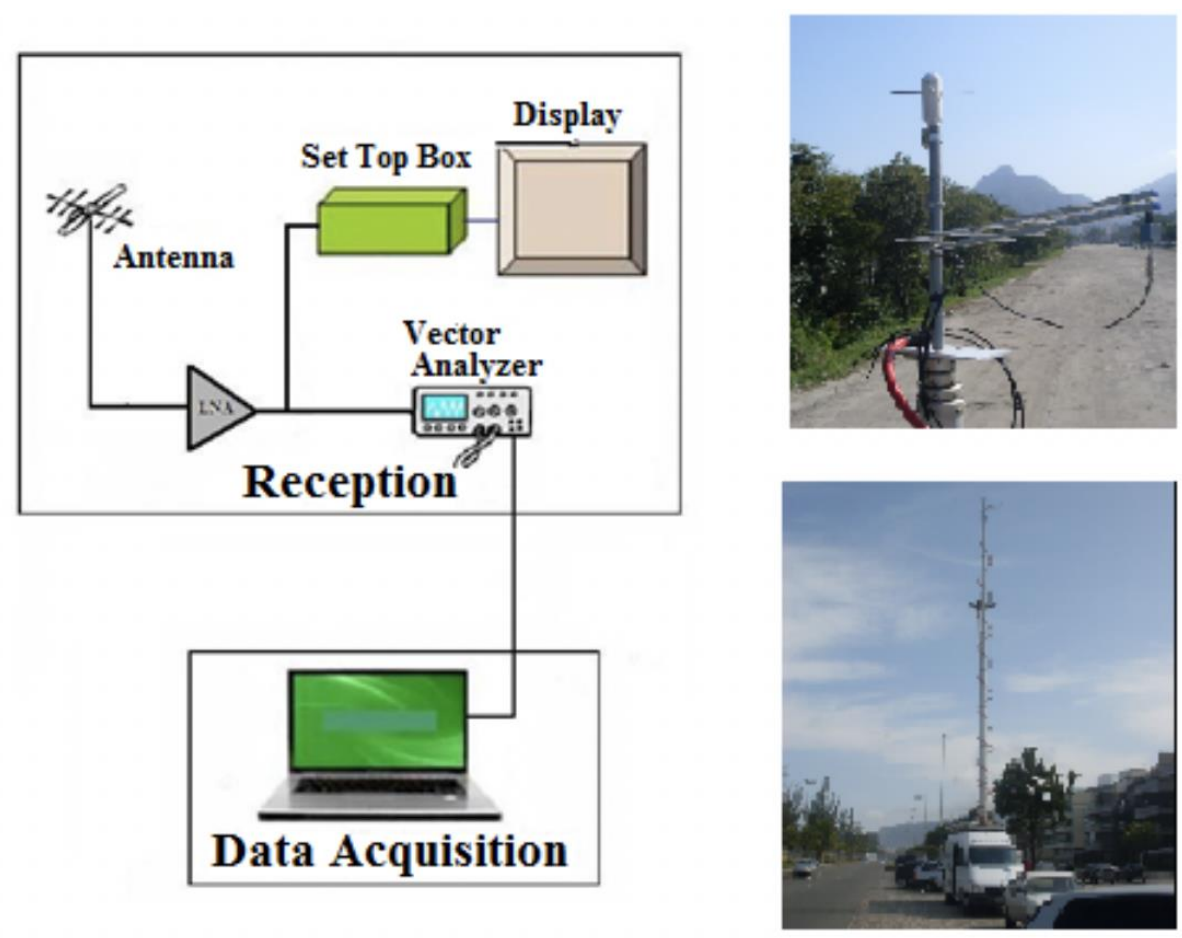

Fig.1 Reception setup, directive reception antenna and the reception van

The measurements were performed on a local TV broadcaster SFN network, with a channel bandwidth of $6 \mathrm{MHz}$ centered at $563 \mathrm{MHz}$. Static measurements were performed at 31 locations with both an omnidirectional and a directional antenna. The directional antenna has a $14 \mathrm{dBi}$ gain with $30^{\circ}$ horizontal and vertical beamwidths. The directional antenna patterns are shown in Fig. 2.

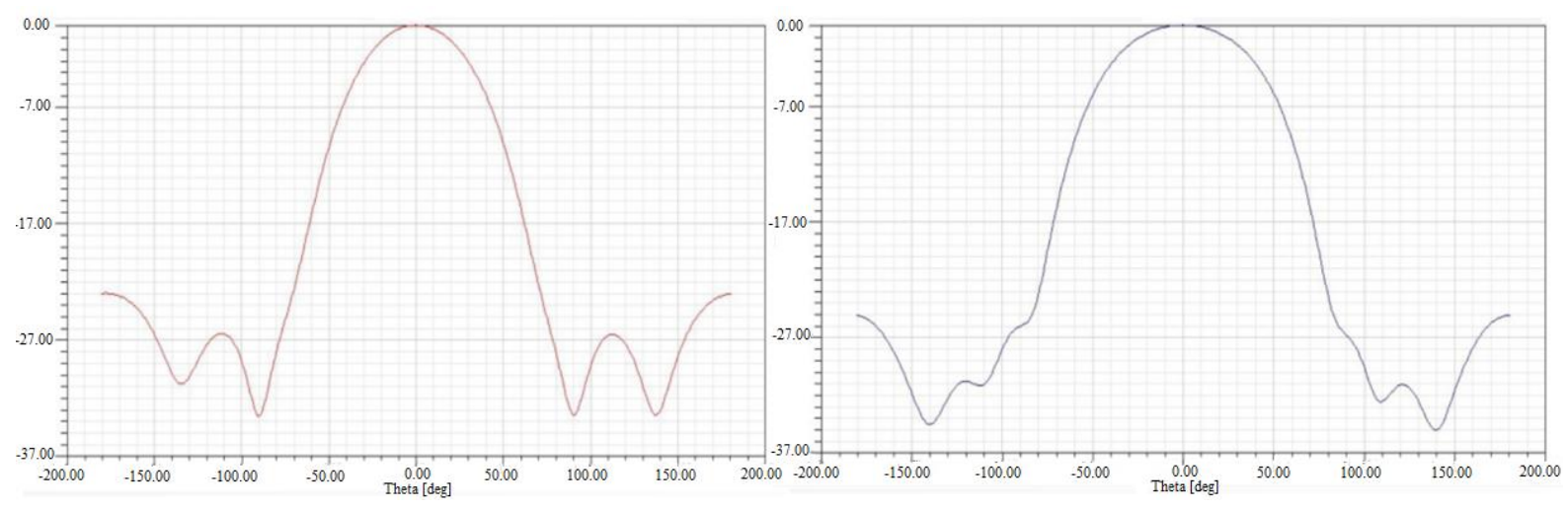

Fig. 2. Directional horizontal (left) and vertical (right) antenna patterns plus measurement setup. 
Journal of Microwaves, Optoelectronics and Electromagnetic Applications, Vol. 18, No. 3, September 2019443 DOI: http://dx.doi.org/10.1590/2179-10742019v18i31778

The ANRITSU MS8901A network analyzer, which is capable of measuring the multipath power delay profile (PDP), was configured to be used as an ISDB-T receiver. Fig. 3 illustrates the measurement of a three-component multipath signal at the receiver.

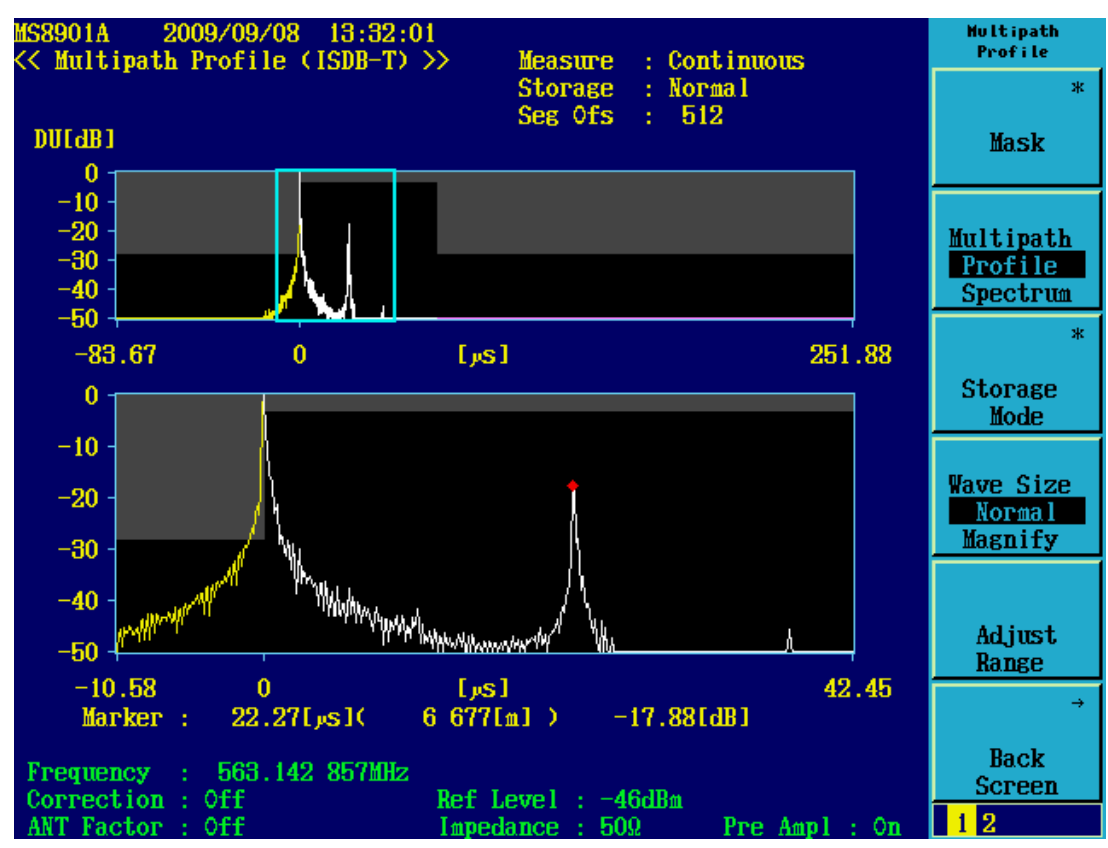

Fig. 3. Measurement of multipath PDP with the network analyzer ANRITSU MS8901A.

During the first round of measurements, the two antennas were positioned $13.4 \mathrm{~m}$ above ground level. For comparison purposes, additional measurements were performed using the omnidirectional antenna positioned $4.1 \mathrm{~m}$ above the ground level. Fig. 4 shows the two transmitter sites and the 31 measurement locations chosen along roads in the coverage area.

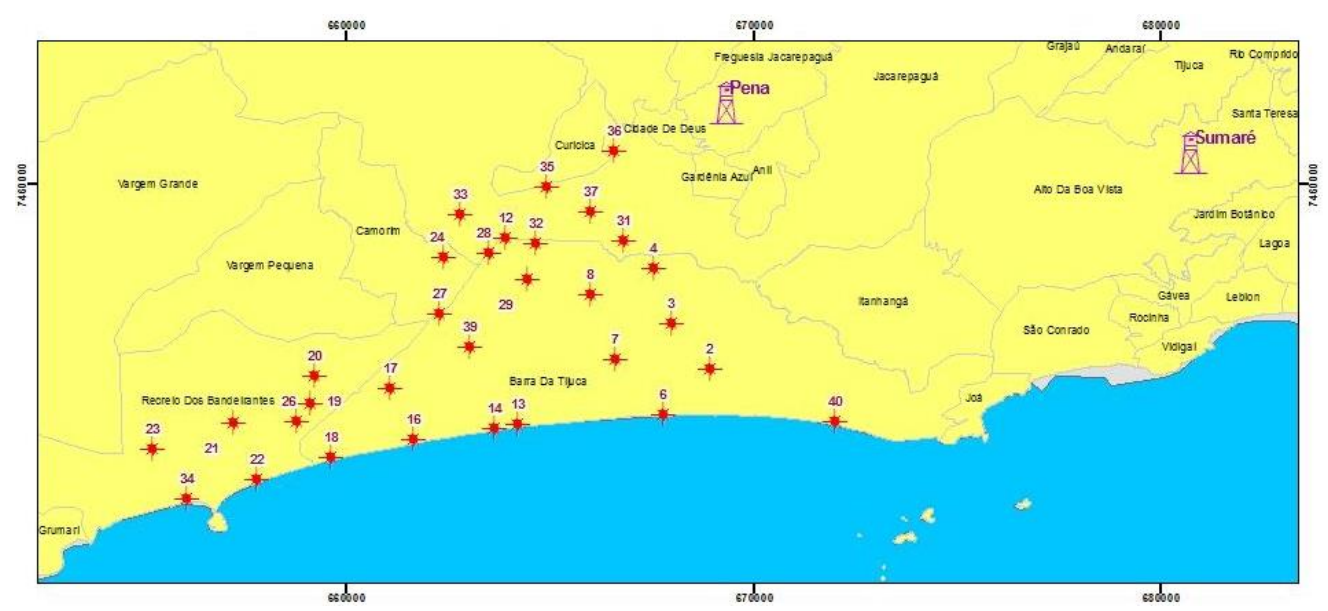

Fig. 4. Transmitter sites and measurement points. 
Journal of Microwaves, Optoelectronics and Electromagnetic Applications, Vol. 18, No. 3, September 2019444 DOI: http://dx.doi.org/10.1590/2179-10742019v18i31778

\section{MULTIPATH CHANNEL CHARACTERISTIC PARAMETERS}

\section{A. Root-Mean-Square Delay Spread (RDS)}

The RDS is the most important single parameter used to characterize the multipath effect in a radio channel. The RDS is defined as the square root of the second central moment of the PDP. It is given by [14]

$$
\begin{gathered}
R D S=\sigma_{r m s}=\sqrt{\frac{\sum_{k}\left(\tau_{k}-\bar{\tau}\right)^{2}}{\sum_{k} P\left(\tau_{k}\right)}}, \\
\bar{\tau}=\frac{\sum_{k} P\left(\tau_{k}\right) \tau_{k}}{\sum_{k} P\left(\tau_{k}\right)},
\end{gathered}
$$

where:

$P\left(\tau_{k}\right)$ is the relative power level of the $k$-th multipath component with respect to the power level of the first component $(k=1)$;

$\tau_{k}$ is the relative time delay of the $k$-th multipath component with respect to the time of arrival of the first component $(k=1)$;

$\bar{\tau}$ is the average excess delay.

The RDS parameter was calculated for each reception point and each reception antenna configuration from the PDPs that were measured, as described in Section II. Examples of PDP values extracted from the measured data are shown in Fig. 5. The points correspond to the multipath components identified by the network analyzer, as illustrated in Fig. 3 for a three-component case. The PDP is normalized taking the first component as reference. The multipath components are delayed and usually have lower power than the first component due to their longer propagation paths and additional reflections and diffractions.

For both reception points with PDPs depicted in Fig. 5, two clusters of multipath components can be clearly identified, corresponding to the signals from each transmitting antenna. Compared to the measured PDP received from a single transmitter, the measured PDPs received from two transmitters had greater spread, and the PDP has long delay echoes owing to the multiple SFN transmitters.
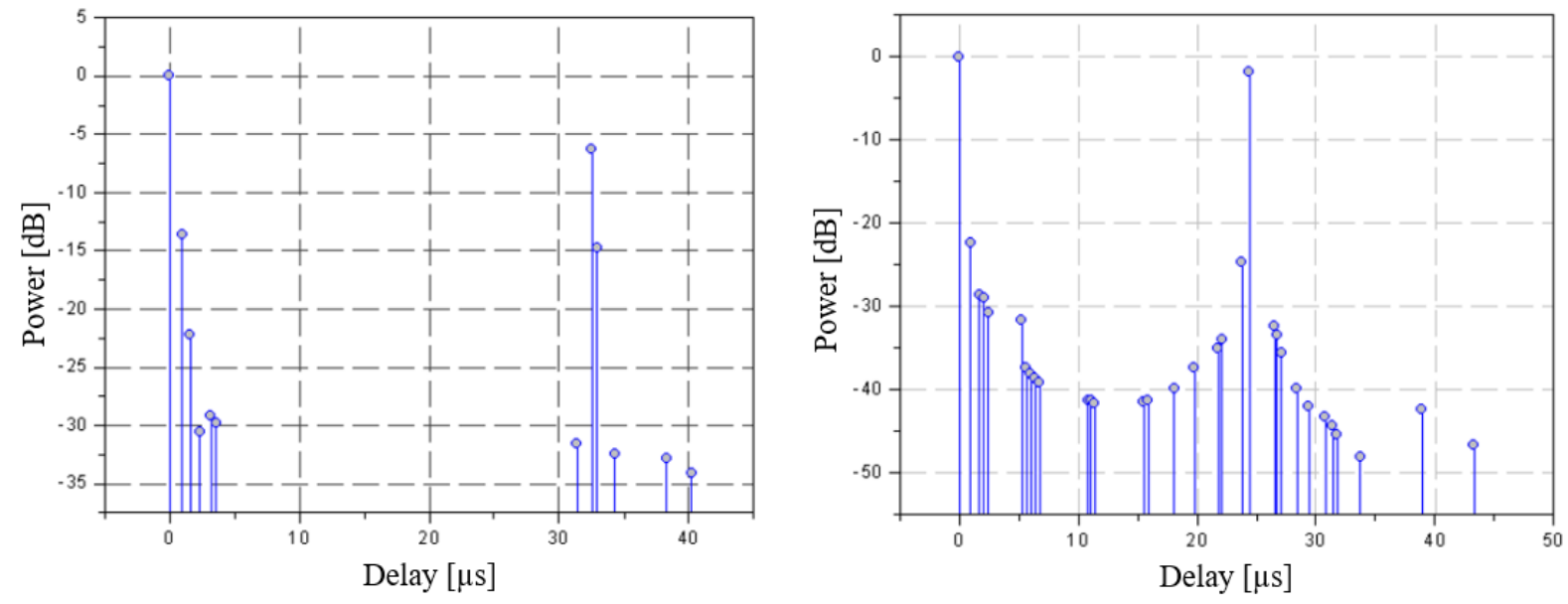

Fig. 5. Power delay profiles measured at points 6 and 16. 
Journal of Microwaves, Optoelectronics and Electromagnetic Applications, Vol. 18, No. 3, September 2019445 DOI: http://dx.doi.org/10.1590/2179-10742019v18i31778

\section{B. Rician K-Factor}

The Rician K-factor [15] is defined as the ratio of the signal power in the dominant component and is also known as the line-of sight (LOS) component over the power of the scattered components.

$$
K=\frac{P_{L O S}}{P_{\text {scatt }}}=\frac{r_{S}^{2}}{2 \sigma^{2}}
$$

where $r_{s}$ is the amplitude of the dominant component of the signal, and $\sigma$ represents the variance of the multipath components. The $\mathrm{K}$-factor is a parameter that is used to quantify the channel fading severity. An accurate characterization of the K-factor is useful in link-budget calculations and in the design of adaptive receivers.

\section{RESULTS}

\section{A. Average delay and RDS}

The delay dispersion parameter was calculated for the 31 measurements points considering the threshold below which the multipath components are ignored. Table III shows the average and maximum values of the average delay and RDS for both omnidirectional and directional antennas at $13.4 \mathrm{~m}$. Thresholds of $-10,-15,-20$, and $-30 \mathrm{~dB}$ below the maximum PDP value were considered.

TABLE III. MEASURED DELAY PARAMETERS FOR TWO SFN TRANSMITTERS.

\begin{tabular}{|c|c|c|c|c|c|c|c|c|}
\hline \multirow[t]{2}{*}{ Threshold } & \multicolumn{2}{|c|}{$\begin{array}{c}\text { Average delay }(\mu \mathrm{s}) \\
\text { omnidirectional } \\
\text { antenna } \\
\end{array}$} & \multicolumn{2}{|c|}{$\begin{array}{c}\text { Average delay ( } \mu \mathrm{s}) \\
\text { directional antenna (Sumaré) }\end{array}$} & \multicolumn{2}{|c|}{$\begin{array}{c}\text { RDS }(\mu \mathrm{s}) \\
\text { omnidirectional } \\
\text { antenna } \\
\end{array}$} & \multicolumn{2}{|c|}{$\begin{array}{c}\text { RDS ( } \mu \mathrm{s}) \text { directional } \\
\text { antenna } \\
\text { (Sumaré) } \\
\end{array}$} \\
\hline & Average & Maximum & Average & Maximum & Average & Maximum & Average & Maximum \\
\hline$-30 \mathrm{~dB}$ & 0.48 & 4.75 & 0.90 & 12.99 & 1.54 & 8.03 & 1.94 & 11.69 \\
\hline$-20 \mathrm{~dB}$ & 0.86 & 4.68 & 1.86 & 12.66 & 2.45 & 8.01 & 3.34 & 11.71 \\
\hline$-15 \mathrm{~dB}$ & 1.16 & 4.55 & 2.36 & 12.65 & 2.84 & 7.99 & 3.53 & 11.71 \\
\hline$-10 \mathrm{~dB}$ & 2.45 & 4.48 & 3.83 & 12.49 & 4.37 & 8.04 & 5.00 & 11.44 \\
\hline
\end{tabular}

As can be seen in Table III, the maximum average delay and RDS values show slight variation with the threshold [16]. Meanwhile, the mean values decrease for lower thresholds as additional components are detected. In addition, the RDS values are higher for directional antenna reception.

At 12 points, measurements were also performed with the omnidirectional antenna positioned $4.1 \mathrm{~m}$ above the ground. Considering only these points, the average value of the RDS was slightly higher (2.24 $\mu \mathrm{s})$ for the measurements with the lower antenna than with the higher antenna $(1.98 \mu \mathrm{s})$.

Considering the maximum values of RDS measured with a -30-dB threshold, as shown in Table III, and the ISDB-T specifications given in Table I, it can be concluded that for portable reception (maximum RDS $=8.03 \mu \mathrm{s})$, the system can operate in mode 1 with a guard interval of $1 / 16(\mathrm{Tg}=15.75$ Brazilian Microwave and Optoelectronics Society-SBMO received 17 May 2019; for review 23 May 2019; accepted 15 Aug 2019 $\begin{array}{llll}\text { Brazilian Society of Electromagnetism-SBMag } & \text { (C) 2019 SBMO/SBMag } & \text { (cc)BY BY } & \text { ISSN 2179-1074 }\end{array}$ 
Journal of Microwaves, Optoelectronics and Electromagnetic Applications, Vol. 18, No. 3, September 2019446 DOI: http://dx.doi.org/10.1590/2179-10742019v18i31778

$\mu \mathrm{s})$, in mode 2 with a guard interval of $1 / 32(\mathrm{Tg}=15.75 \mu \mathrm{s})$, and in mode 3 with a guard interval of $1 / 32(\mathrm{Tg}=31.5 \mu \mathrm{s})$, thus maximizing the spectral efficiency of the system [8]-[11].

The use of more than one transmitter, although improving the coverage [17],[18], can produce additional multipath at the receiver, and is known as the SFN effect. However, lower average and maximum values of RDS are observed for the omnidirectional antenna, as shown in Table III. This is due to the higher gain of the directional antenna, which will enhance multipath components, and will be negligible for the lower-gain omnidirectional antenna [19].

Figure 6 shows the measured values of the average delay and RDS at each point plotted as a function of the distance to the Sumaré transmitter. For this set of measurements, the directional antenna was pointed towards the Sumaré transmitter. Both antennas were $13.4 \mathrm{~m}$ above ground level. From this plot, it is not possible to infer any trend of these parameters with the distance to main transmitter. However, there is a definite trend in the relation between the average delay and RDS, as shown in Fig. 7.

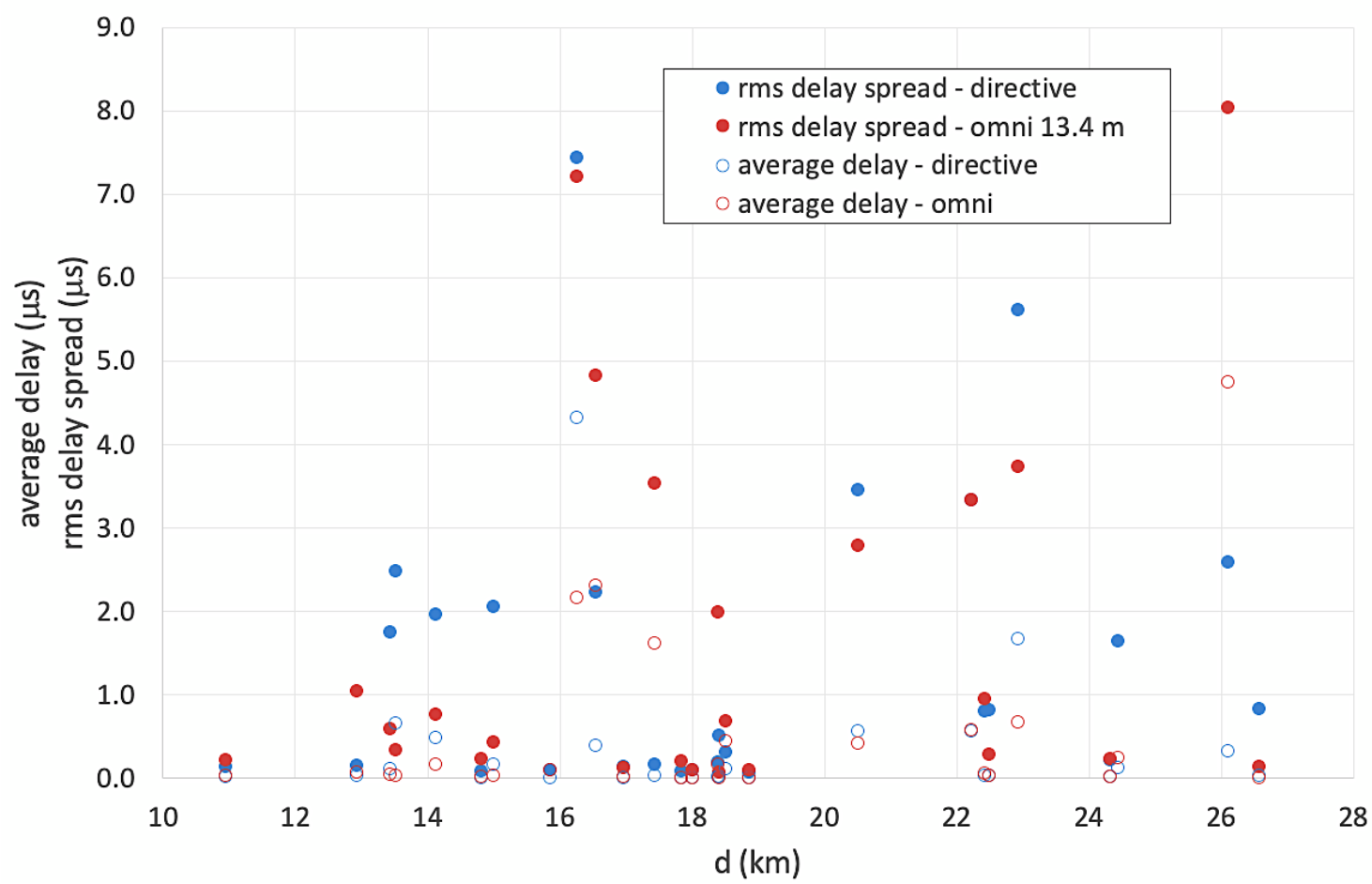

Fig. 6. Average delay and RDS values versus distance (to Sumaré) for the directional and omnidirectional antennas. 
Journal of Microwaves, Optoelectronics and Electromagnetic Applications, Vol. 18, No. 3, September 2019447 DOI: http://dx.doi.org/10.1590/2179-10742019v18i31778

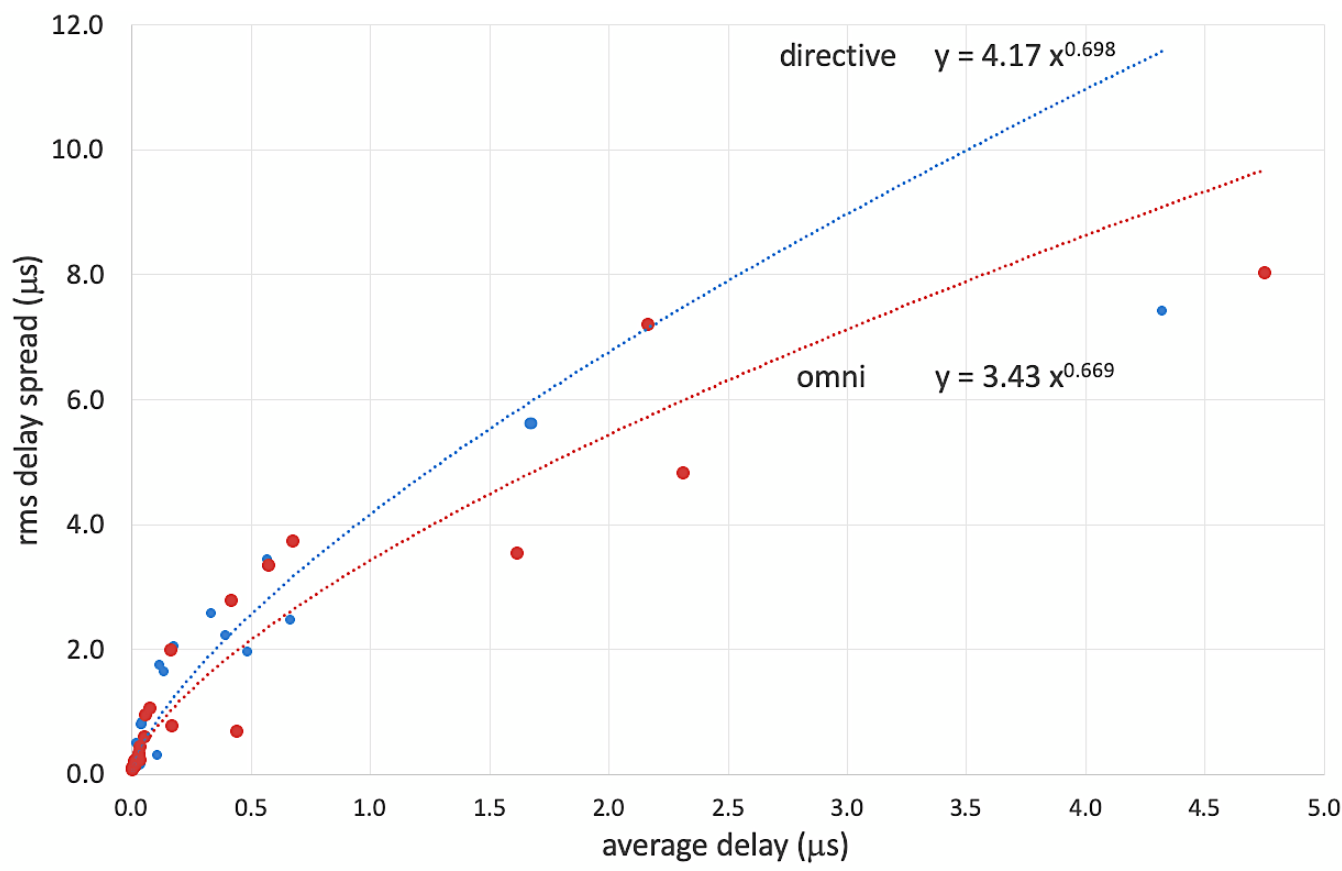

Fig. 7. RDS versus average delay: directional and omnidirectional antennas.

\section{B. Dependence of delay parameters on the K factor}

The values of the $\mathrm{K}$ factor for the directional and omnidirectional antennas are consistent, as shown in Fig. 8, particularly for high values corresponding to the dominance of a direct component. Note that the measured $\mathrm{K}$ factor values vary from 5 to approximately 30 , corresponding to $\mathrm{K}$ between -3 to 4.8 $\mathrm{dB}$. The results also show that the average delay and RDS clearly decrease as the K factor increases, as shown in Figs. 9 and 10. This is expected as in the presence of a strong dominant multipath component, less delay spread will occur.

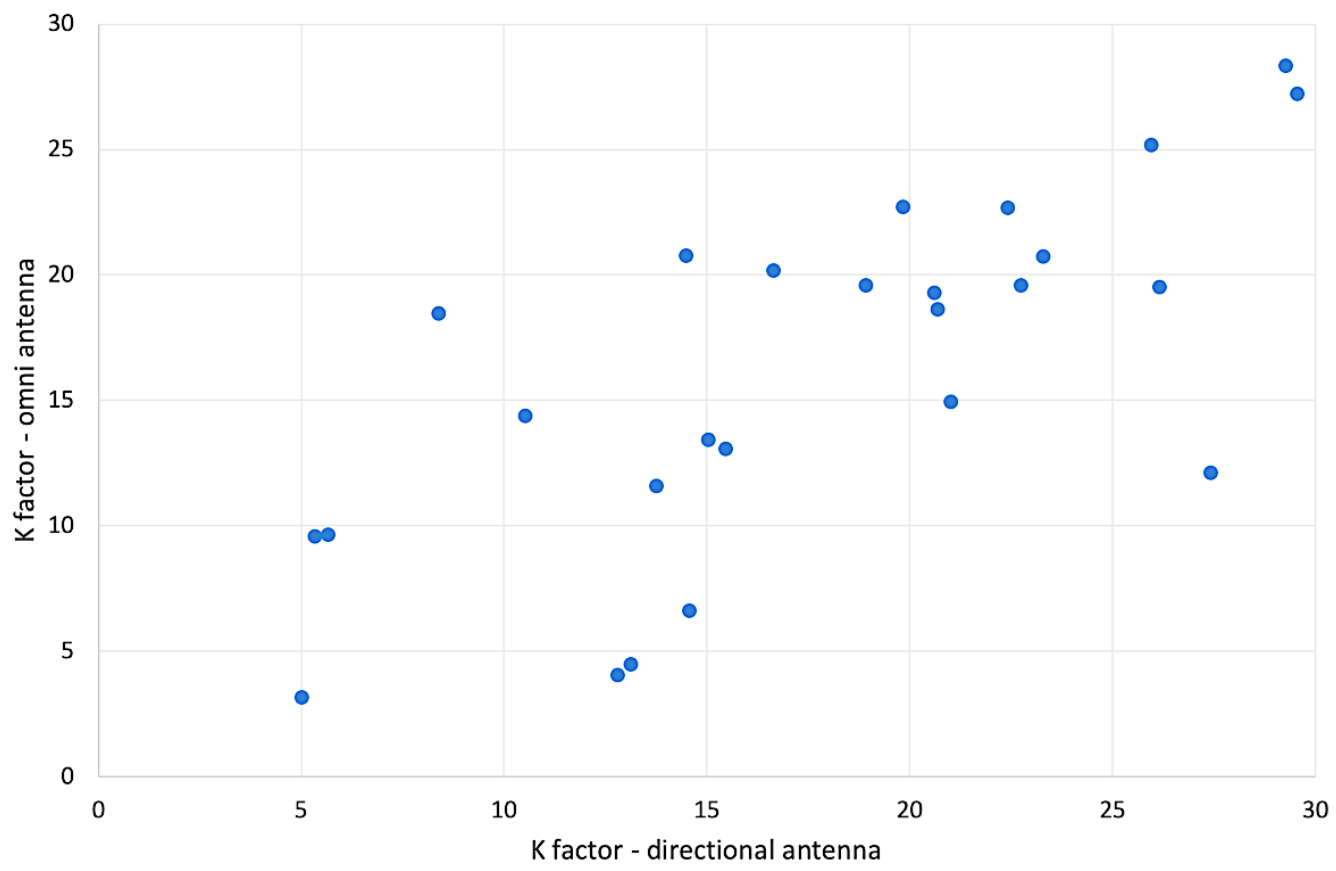

Fig. 8. Omnidirectional antenna $\mathrm{K}$ factor versus directional antenna $\mathrm{K}$ factor. 
Journal of Microwaves, Optoelectronics and Electromagnetic Applications, Vol. 18, No. 3, September 2019448 DOI: http://dx.doi.org/10.1590/2179-10742019v18i31778

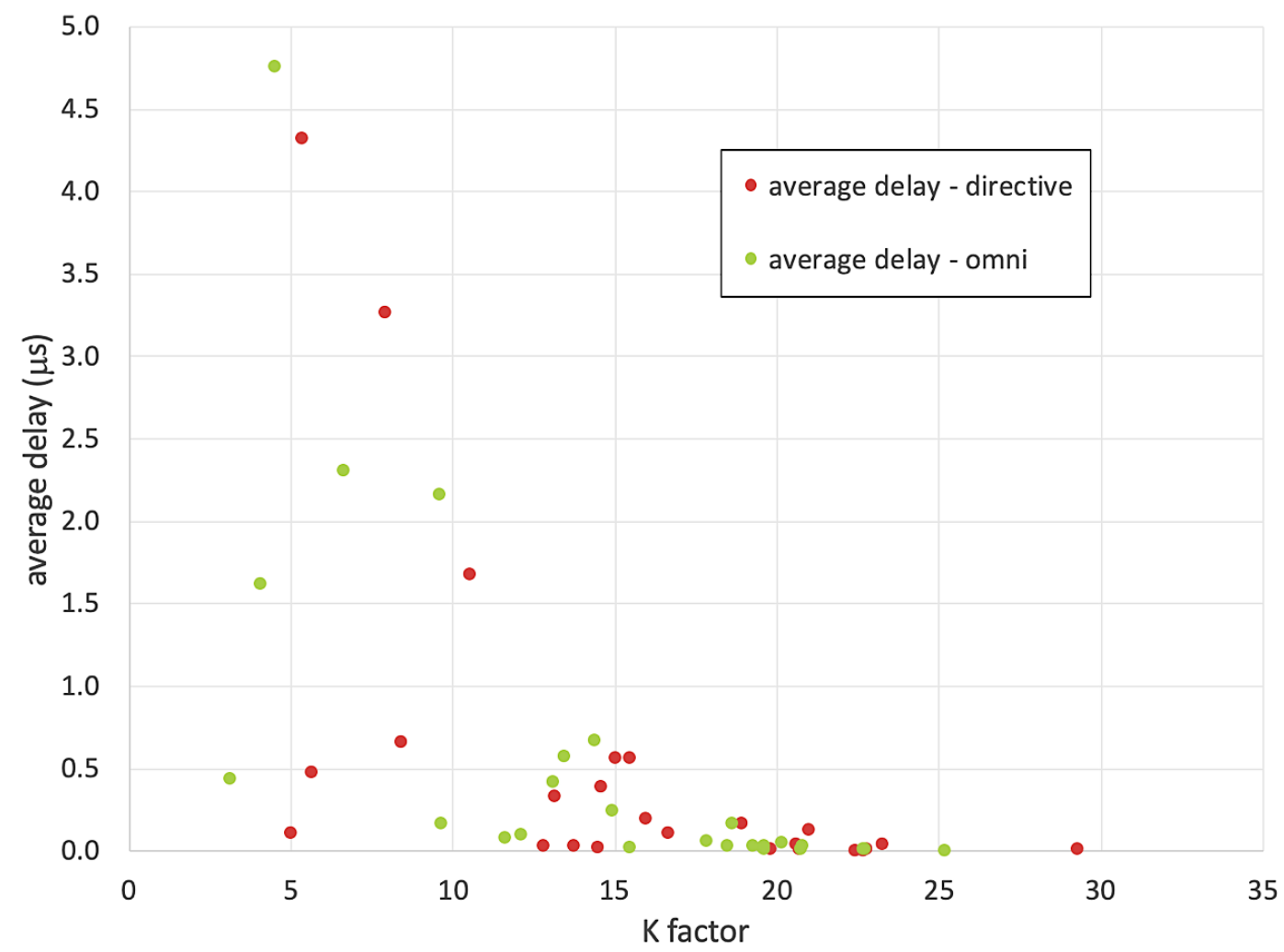

Fig. 9. Average delay vs. K factor for omnidirectional and directional antennas.

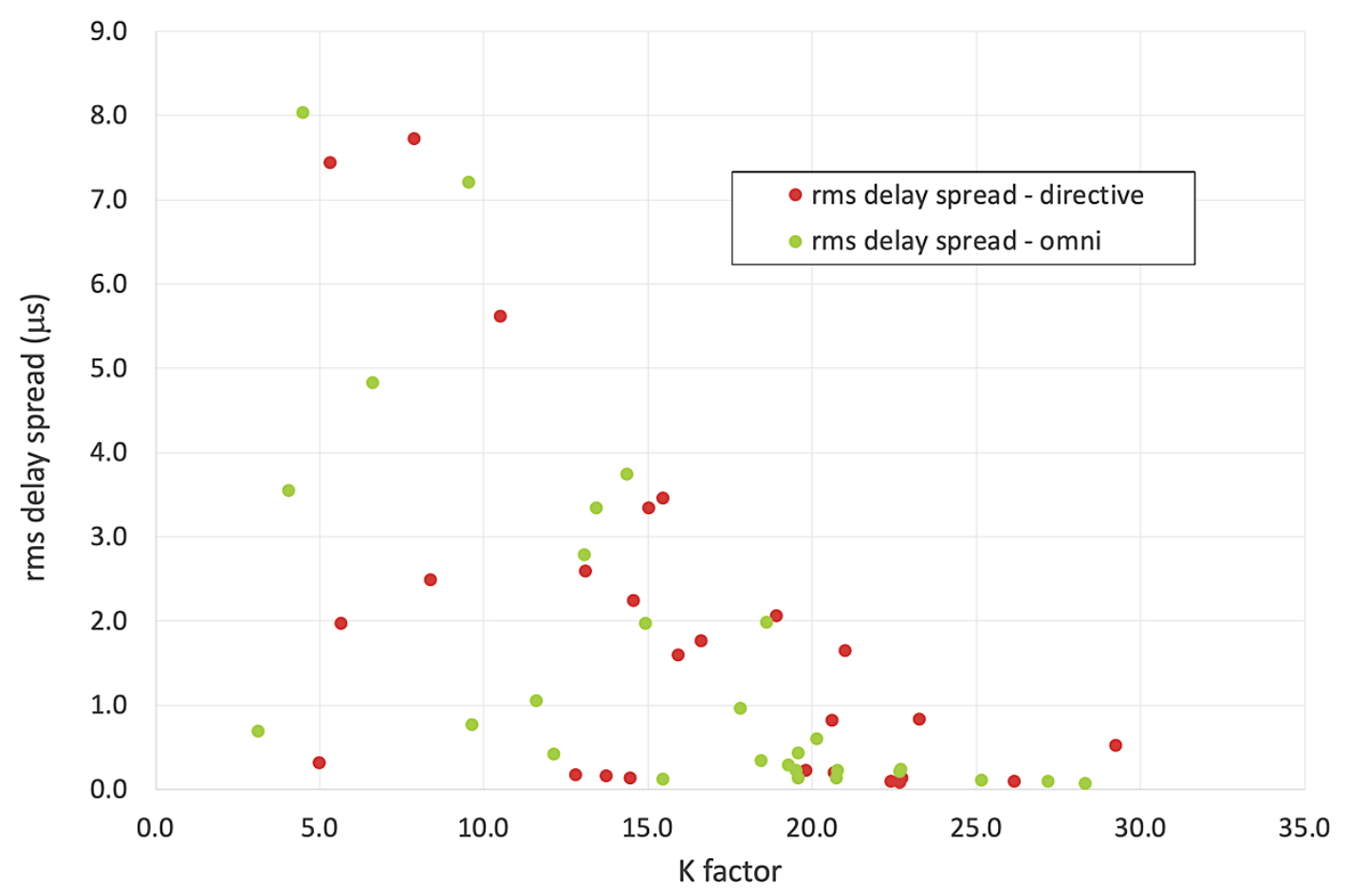

Fig. 10. RDS vs. K factor for omnidirectional and directional antennas. 
Journal of Microwaves, Optoelectronics and Electromagnetic Applications, Vol. 18, No. 3, September 2019449 DOI: http://dx.doi.org/10.1590/2179-10742019v18i31778

In addition, if the RDS is plotted against the distances to the main antenna and the auxiliary antenna of the SFN network, as shown in Fig. 11, a slight trend of the RDS to increase with distance can be observed. In this figure, $\mathrm{d}<$ corresponds to the smaller distance to an antenna, and $\mathrm{d}>$ corresponds to the largest distance to an antenna.

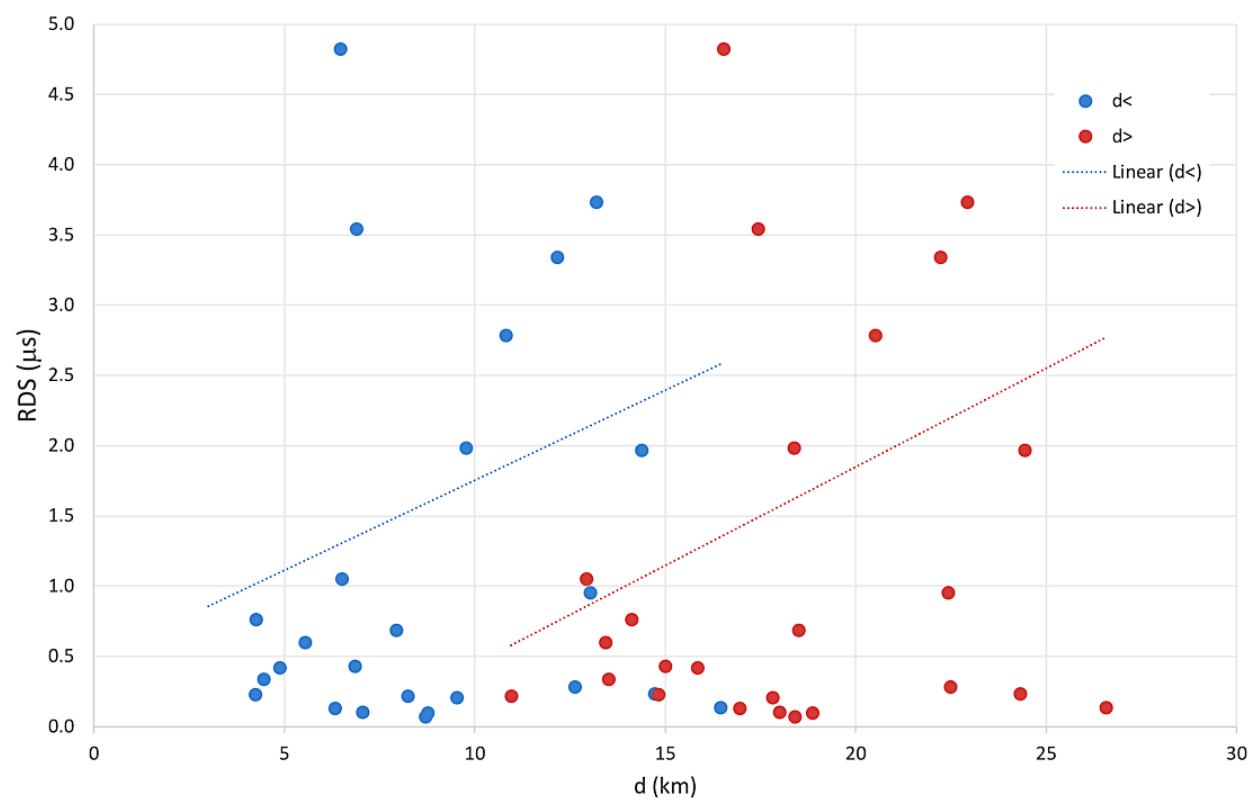

Fig. 11. RDS vs. distance to the antennas.

The results indicate that it is possible to derive an empirical expression to estimate the values of RDS based on these distances and the $\mathrm{K}$ factor. Based on the behavior of the RDS with the $\mathrm{K}$ factor, observed in Fig. 10, and with the distances to the antennas, observed in Fig. 11, an expression given by the product of an exponential function of $\mathrm{K}$ and power functions of the distances was adjusted to the data with coefficients obtained by least square fitting. The expression obtained is

$$
R D S(\mu s)=0.195 \exp (-0.096 K)\left(d_{<}^{0.93}+d_{>}^{1.3}\right)
$$

where the distances are given in km. Fig. 12 shows a comparison of the measured values and the values that are predicted using this expression. 
Journal of Microwaves, Optoelectronics and Electromagnetic Applications, Vol. 18, No. 3, September 2019450 DOI: http://dx.doi.org/10.1590/2179-10742019v18i31778

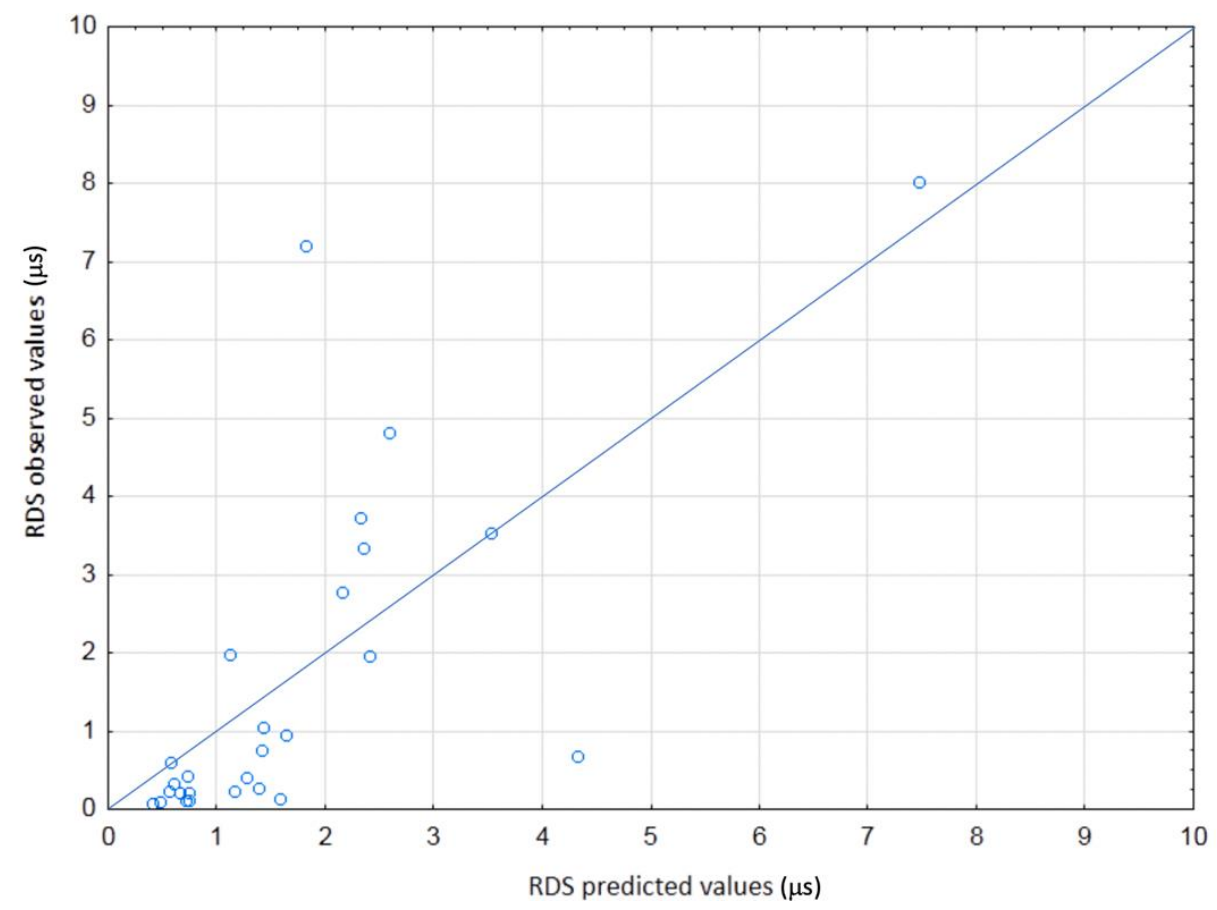

Fig. 12. Observed RDS vs. predicted values.

Considering the limited number of measurement points and the specific configuration of the experiment, additional measurements will be required to verify this expression.

\section{CONCLUSIONS AND FURTHER WORK}

Delay spread parameters have been obtained from measured PDPs collected during a measurement campaign using a two-transmitter TV broadcast SFN that covers a suburban area of the city of Rio de Janeiro and its surroundings. Recommendation ITU-R REC. P.1407 definitions were used to calculate the average delay and the RDS. The method that was employed allows measurements to be carried out in operating networks and can be used in further measurement campaigns to be performed in the future.

Directional and omnidirectional antennas that are positioned $13.4 \mathrm{~m}$ above the ground were used in the measurements at the same 31 points inside the coverage area. The directional antennas can be used for fixed reception, whereas omnidirectional antennas are used for mobile reception.

The results include mean and maximum values of the average delay and RDS for different measurements thresholds, and the Rician K-factor, which is defined as the ratio of the signal power in the dominant component over the power of the scattered components. The maximum values of the average delay and RDS vary only slightly with the threshold, but their mean values decrease for lower thresholds as additional components are detected. Further, the RDS values are higher for the directional antenna case owing to its higher gain.

The relationship between the variation of the reception conditions and the SFN effect has also been considered. At some points, measurements were performed with the omnidirectional antenna positioned $4.1 \mathrm{~m}$ above the ground. Considering only these points, the average value of the RDS was slightly higher for the measurements with the lower antenna than with the higher antenna. 
Journal of Microwaves, Optoelectronics and Electromagnetic Applications, Vol. 18, No. 3, September 2019451 DOI: http://dx.doi.org/10.1590/2179-10742019v18i31778

The relation between the RDS and the K-factor was analyzed. The SFN fading signal followed a Rician distribution owing to the existence of a line-of-sight (LOS) component from either or both transmitting antennas at almost all reception points. Results show that the average delay and RDS clearly decrease as the $\mathrm{K}$ factor increases. In addition, a trend of the RDS to increase with the distances to the two transmitting antennas was observed. It was possible to derive a simple empirical expression to estimate the values of RDS based on these distances and the $\mathrm{K}$ factor. This estimator can be useful because it is easier to measure the $\mathrm{K}$ factor than the RDS, which needs to be obtained from the PDPs. However, additional measurements will be required to verify this expression.

\section{REFERENCES}

[1] M. Guerra, "Experimental Characterization of a SFN Digital Broadcast Channel," IEEE Latin-America Conf. on Commun., Cuenca, Ecuador, pp. 1-4, 2012.

[2] V. Ricny, "Single Frequency Networks (SFN) in Digital Terrestrial Broadcasting," Radioengineering, vol. 16, no. 4, pp. 2-6, 2007.

[3] P. Vasileiou, "Planning Single Frequency Networks for Broadcasting Digital TV," Eur. Conf. on Antennas and Propag., Gothenburg, Sweden, pp. 3488-3492, 2013.

[4] C. Li, "Planning Large Single Frequency Networks for DVB-T2," IEEE Trans. on Broadcast., vol. 61, no. 3, pp. 376$387,2015$.

[5] B. Ruckveratham, "Evaluation of SFN Gain for DVB-T2," Proc. Int. Conf. on Digital Arts, Media and Technol., Chiang Mai, Thailand, pp1-4, 2017.

[6] B. Ruckveratham. "A Study of Single Frequency Network for DVB-T2 base on Measurement Data," Global Wirel. Summit, Chiang Rai, Thailand, pp. 379-382, 2018.

[7] S. Promwong, "Modulation Error Ratio Gain of Single Frequency Network in DVB-T2," Proc. Int. Conf. on Digital Arts, Nan, Thailand, pp. 128-131, 2019.

[8] L. Polak, "SISO/MISO Performances in DVB-T2 and Fixed TV Channels," Proc. Int. Conf. on Telecommun. and Signal Process., Prague, Czech Republic, pp. 768-771, 2015.

[9] L. Polak, "DVB-T and DVB-T2 Performance in Fixed Terrestrial TV Channels," Proc. Int. Conf. on Telecommun. and Signal Process., Prague, Czech Republic, pp. 725-729, 2012.

[10] D. Tralic, "Simulation and Measurement of DVB-T2 Channel Characteristics," Proc. Int. Conf. ELMAR-2012, Zadar, Croatia, 2012.

[11] J. Morgade, "A Measurement-based Methodology for the DVB-T2 MISO/SISO Gain Characterization in Experimental Networks," Proc. Int. Conf. on Electromagn. in Adv. Appl., Torino, Italy, pp. 487-490, 2013.

[12] M. Takada, and S. Masafumi, "Transmission System for ISDB-T,” Proc. of the IEEE, vol. 94, no. 1, pp. 251-256, 2006.

[13] Terrestrial Integrated Services Digital Broadcasting (ISDB-T) Document, Specification of Channel Coding, Framing Structure and Modulation, 1998.

[14] ITU Recommendation ITU-R P. 1407: Multipath Propagation and Parameterisation of its Characteristics, 1999.

[15] J. D. Parsons, The Mobile Radio Propagation Channel, Pentech Press, London, 1994, p. 139.

[16] L. Eizmendi, "Empirical DVB-T2 Thresholds for Fixed Reception," IEEE Trans. on Broadcast., vol. 59, no. 2, Jun, pp. 306-316, 2013.

[17] DVB BlueBook A133, "Implementation Guidelines for a Second-generation Digital Terrestrial Television Broadcasting System (DVB-T2)," February 2009.

[18] DVB Document A122, "Frame Structure Channel Coding and Modulation for a Second-generation Digital Terrestrial Television Broadcasting System (DVB-T2)," June 2008.

[19] L. Zhang, L. Gui, and W. Zhang, "Obtaining Diversity Gain for DTV by Using MIMO Structure in SFN," IEEE Trans. Broadcast., Vol. 50, No. 1, Mar. 2004. Proc. Int. Conf. on, Prague, Czech Republic, pp. 725-729, 2012. 